\title{
JÓVENES Y PARTICIPACIÓN POLÍTICA FLEXIBLE: COOPERATIVISMO EN TIEMPOS DEL CAPITAL HIPERMÓVIL
}

\section{Youth and Flexible Political Participation: Involvement in Cooperatives in Times of Hypermobile Capital}

\author{
Sergio E. Echeverry-Díaz* \\ Juan Pablo Zebadúa-Carbonell ${ }^{* *}$ \\ Héctor Rolando Chaparro-Hurtado*** \\ DOI: https://doi.org/10.29043/liminar.vl8i2.764
}

\begin{abstract}
Resumen: A partir de un estudio etnográfico se da cuenta del modo en que las sociedades cooperativas dedicadas al mejoramiento social son un recurso empleado por algunos sectores de jóvenes para emprender luchas contra las desigualdades que se producen en los dominios material y simbólico y para insertarse laboralmente en un orden social condicionado por las dinámicas de un capitalismo global hipermóvil. Se expone que, si bien estos jóvenes expresan una distancia con respecto a los actores de la política tradicional — partidos políticos, instituciones gubernamentales, etcétera-, operan bajo una lógica flexible en tanto trazan relaciones circunstanciales de interdependencia con estos para agenciar sus proyectos.
\end{abstract}

Palabras clave: jóvenes, ciudadanía política, sociedades cooperativas, globalización, capitalismo.

Abstract: This ethnographic study analyzes how cooperative societies that aim to improve people's living standards are a resource used by young people both to struggle against inequalities that exist in the material and symbolic domains and to join the labor force in a social order shaped by hypermobile global capitalism. Although young people keep a cautious distance from traditional political actors (political parties, government institutions, etc.), they act flexibly and maintain circumstantial interdependent relations with these entities in order to further their plans and projects.

Keywords: youth, political citizenship, cooperative societies, globalization, capitalism.

\footnotetext{
* Sergio E. Echeverry Díaz. Doctorando en Estudios Regionales y maestro en Estudios Culturales por la Universidad Autónoma de Chiapas, México. Temas de especialización: jóvenes, identidades, ciudadanías, corporalidades y violencia. Correo electrónico: sergiodiaz1991@outlook. com. ORCID: https://orcid.org/0000-0002-0959-9174

** Juan Pablo Zebadúa Carbonell. Doctor en Estudios Interculturales por la Universidad de Granada, España. Profesor e investigador en la Universidad Autónoma de Chiapas, México. Temas de especialización: jóvenes, consumos culturales, globalización e identidades. Correo electrónico: jpcarboney@gmail.com. ORCID: https://orcid.org/00000003-3598-3900
}

\begin{abstract}
*** Héctor Rolando Chaparro Hurtado. Doctor en Estudios Sociales de América Latina por la Universidad Nacional de Córdoba, Argentina. Profesor e investigador en la Facultad de Ciencias Humanas y de la Educación, Universidad de los Llanos, Argentina. Temas de especialización: jóvenes, educación y cultura, identidades, corporalidades, cultura y sociedad. Correo electrónico: rotundol823@gmail.com. ORCID: https://orcid.org/0000-0003-0267-612X
\end{abstract}

Enviado a dictamen: 17 de septiembre de 2019. Aprobación: 18 de enero de 2020.

Revisiones: 1. 


\section{Introducción}

$\mathrm{H}$ oy en día los jóvenes ocupan un papel protagónico en las dinámicas globales de transformación sociopolítica. Si bien en otros tiempos las luchas por la construcción de la igualdad fueron emprendidas por otros actores, actualmente son estos quienes, desde distintas trincheras, reclaman transformaciones. Así, en un mundo estructurado a partir de redes tecnoinformáticas, circuitos globales de flujos financieros e incertidumbre económica, la juventud busca insertarse eficazmente y emprender proyectos de mejoramiento social.

En efecto, para entender las formas de participación juvenil que emergen en la actualidad es preciso contemplar que los jóvenes no son un sujeto universal. En su lugar conviene interpretarlos desde tres acepciones conexas: como símbolo-dispositivo, en referencia a que cada sociedad construye una serie de significaciones, ordenamientos y espacios de poder para ellos; como posibilidad, en alusión a que no están determinados, sino acaecen como contingencia espaciotemporal; y como agentes, en tanto cuentan con capacidad para impactar en la construcción de la experiencia colectiva. Al lado de ello, prevalece analizar los desplazamientos que vienen ocurriendo en el ámbito de la participación ciudadana, puesto que es allí donde estos actores están resignificando sus sentidos de pertenencia, la lucha por la equidad y la consolidación de formas de vida más democráticas e inclusivas.

En relación con lo último, cabe señalar que cuando se habla de ciudadanía se hace referencia a un nexo de pertenencia y participación de un individuo hacia una comunidad política que le emplaza a jugar un papel activo defendiendo, ampliando y respetando la igualdad dentro de esta (Ramírez, 2011). A grandes rasgos, se trata de un recurso de organización social creado en la cultura moderna para vincular a las personas a una unidad político-administrativa de naturaleza macro, conocida como Estado nacional.
Entre los siglos XVIII y XX los Estados nacionales se consolidaron como soporte de identidades comunitarias, reforzadas mediante el otorgamiento de derechos y deberes universales. En tal panorama, el ciudadano se figuró sobre el compromiso con el buen funcionamiento de los valores, principios y mecanismos instituidos; para permitir la intervención en las dinámicas administrativas del poder se estableció un conjunto de prácticas insertas institucionalmente dentro un sistema representativo de organización política - procesos electorales, consultas ciudadanas, consejos, partidos políticos, sindicatos, etcétera- (Benedicto y Morán, 2003).

No obstante, hoy en día, a raíz de los descentramientos provocados por los procesos de globalización, la consolidación del modelo económico neoliberal, el deterioro del estado de bienestar y la ineficiencia de las instituciones de la democracia representativa para garantizar la construcción y resguardo de la igualdad, se ha extendido un descreimiento generalizado hacia el Estado nacional y los mecanismos de participación modernos (Corporación Latinobarómetro, 2016; Giddens, 2000). De este modo, si bien el sistema político representativo sigue siendo el modelo de participación dominante, coexiste con una apatía generalizada hacia él y con la emergencia de distintas alternativas de participación ciudadana emprendidas, en su mayoría, por actores jóvenes.

En tal contexto, este ensayo ofrece una reflexión sobre el modo en que las sociedades cooperativas se convierten, hoy en día, en una estrategia empleada por muchos jóvenes del sur de México para negociar, gestionar y producir su participación política en las dinámicas del capitalismo global hipermóvil. Lo expuesto aquí es resultado de un estudio etnográfico que tuvo como objeto analizar los procesos de construcción de ciudadanías políticas de un grupo de jóvenes integrantes de una cooperativa ${ }^{1}$ dedicada al fomento de las artes en dos colonias populares de la ciudad de Tuxtla Gutiérrez, Chiapas, las colonias Bienestar Social ${ }^{2}$ y Las Palmas. ${ }^{3}$ 


\section{Metodología}

Esta investigación se llevó a cabo entre agosto de 2015 y agosto de 2017. Durante la primera fase se realizó un proceso de recolección y análisis cualitativo de documentos relacionados con el tema de las ciudadanías políticas, las juventudes, la globalización y la realidad política, económica y cultural de Tuxtla Gutiérrez, Chiapas; esto permitió consolidar el marco referencial desde donde se analizó el objeto de estudio.

Posteriormente, se entabló contacto con distintas cooperativas juveniles de la ciudad. Para la selección de la agrupación a estudiar se tuvo en cuenta que sus integrantes: mostraran sentidos de pertenencia y lealtad hacia alguna comunidad de la ciudad, pusieran en juego acciones destinadas a generar procesos de mejoramiento social, hicieran explícito un sentimiento de descreimiento hacia las formas tradicionales de participación política, tuvieran una trayectoria mínima de dos años y hubieran consolidado sistemas o estrategias que les permitieran ser sostenibles como organización.

A continuación se diseñaron las técnicas de recolección - entrevista a profundidad y diario de campo - en procura de obtener información sobre las trayectorias individuales y colectivas de los integrantes, las prácticas y sentidos construidos como agrupación y las formas de gestión y negociación con las estructuras locales. Se buscó generar un acercamiento desde la triangulación de tres observables: los actores, el contexto, y las estrategias y recursos de negociación de los primeros con lo segundo.

Para llevar a cabo la recolección de datos se optó por el método etnográfico, lo que permitió analizar los procesos de construcción ciudadana de estos jóvenes a partir de una estancia prolongada con ellos. Así, entre agosto y diciembre de 2016 se consolidó una descripción densa de sus prácticas, sentidos y los procesos cotidianos que movilizan, conflictúan y problematizan su experiencia como cooperativa. En total se aplicaron catorce entrevistas a profundidad distribuidas entre los miembros fundadores - aún activos-, los integrantes que se anexaron posteriormente y personas que trabajaron como colaboradores externos o fueron sido testigos de la trayectoria de esta organización. La duración de las entrevistas osciló entre 20 y 50 minutos. Por su parte, los diarios de campo permitieron registrar conversaciones sostenidas por fuera de las entrevistas y las acciones que realizaban en su cotidianidad. Finalmente, se inició la fase de codificación, análisis y organización de los resultados.

\section{Tuxtla Gutiérrez, Chiapas, en tiempos del capitalismo hipermóvil}

Para delimitar el contexto de la investigación se tuvieron en cuenta una serie de tensiones socioculturales que dan forma a la ciudad de Tuxtla Gutiérrez como comunidad imaginada; en esta oportunidad, atendiendo a los intereses del ensayo, se hará mención exclusiva de los modos en que se entrecruzan procesos locales de desigualdad e incertidumbre económica con las formas en que se moldean los actuales circuitos transnacionales de mercado.

Atendiendo a ello, hay que tener en cuenta que Tuxtla Gutiérrez es la capital de Chiapas, estado ubicado al sur de México que se ha distinguido por sus condiciones históricas de rezago económico, político y social y por ocupar las posiciones menos aventajadas en comparación con el resto del país. Al igual que otros estados del sur, como Oaxaca y Guerrero, el territorio chiapaneco es mayoritariamente rural, con una población que expone niveles de pobreza y marginalidad que superan el $70 \%$ en casi todos sus municipios (Aguilar, 2016; CONEVAL, 2019).

Si bien la población del estado es heterogénea, gran parte de ella la componen sectores campesinos e indígenas. De hecho, es uno de los territorios que alberga mayor cantidad de pueblos indígenas del país, con una población cercana a 1706 017, que representa el 14.2\% del total de habitantes (CDI, 2017). La mayor parte de esta población vive en circunstancias de carencias socioeconómicas que se materializan en elevadas tasas de pobreza, atraso y vulnerabilidad.

Esta realidad socioeconómica se corresponde con la exclusión que han soportado históricamente los 
territorios campesinos e indígenas de México. Si bien este fenómeno se ha reproducido a nivel continental, como vestigio de los procesos de colonización occidental, hasta la fecha sigue vertebrando los sistemas socioculturales del estado, con el agravante de la ineficaz o escasa intervención de las instituciones encargadas de garantizar el desarrollo social. Por tal motivo, a pesar de que la ciudad de Tuxtla Gutiérrez es uno de los pocos nodos de desarrollo urbano eindustrial de la región, sus tasas de rezago socioeconómico siguen siendo elevadas. Según el Consejo Nacional de Evaluación de la Política de Desarrollo Social (CONEVAL, 2015), cerca de un $41.9 \%$ de sus habitantes se encuentran en situación de pobreza.

En tal contexto, si se tiene en cuenta que el actual involucramiento transnacional conocido como globalización se caracteriza por fenómenos económico-políticos como lo son la hiperaceleración de los flujos financieros y capitales transnacionales y la descentralización del Estado de su lugar como regulador de las economías nacionales y asegurador del bienestar y mejoramiento social (Beck, 2008; Giddens, 2000), se encontrará que Chiapas ha asumido estos cambios desde una posición histórica desigual. Esta situación ha llevado a que gran parte de sus habitantes experimenten un sentimiento de inseguridad económica como consecuencia del incremento de las dificultades de inserción laboral, el desmantelamiento de los derechos sociales, la desigualdad de oportunidades y la maximización de las relaciones de competencia.

La experiencia vivida de los habitantes de Tuxtla Gutiérrez oscila entre procesos de estructuración nacional que han ubicado a Chiapas en una posición periférica y dinámicas de estructuración global definidos a partir de la consolidación de un modelo de mercado caracterizado por la nula intervención estatal en las economías locales, la reducción del gasto público destinado al mejoramiento social y la hiperaceleración de los flujos del capital. ${ }^{4}$ Luego, lo que para aquellas capas sociales que cuentan con los medios para ir a la velocidad de los capitales resulta en una licuefacción de los espacios y los tiempos, para otros deriva en una solidificación sin precedentes de los mismos (Bauman, 2001), puesto que deben incorporarse en una sociedad marcada por relaciones de competencia más fuertes, ritmos de vida más acelerados y un detrimento de los derechos sociales y garantías de protección tradicionales (Beck, 2008). Efectivamente, todo ello se materializa en el surgimiento de nuevas brechas entre los segmentos sociales que se pueden adaptar a los nuevos ritmos financieros y aquellos que no. En otras palabras, en un contexto donde el capital se vuelve hipermóvil, aquellos que no pueden ir a su velocidad son relegados a una posición de rezago, dificultad de movilidad social y vulnerabilidad.

En ese orden de ideas, puede identificarse en Tuxtla Gutiérrez una generación joven subjetivada y socializada en un contexto de incertidumbre económica y un marcado descreimiento hacia las instituciones políticas encargadas de garantizar la inclusión y la igualdad social. Tales condiciones son el germen de un conjunto de propuestas de organización e intervención ciudadana que emergen desde estos actores.

\section{Resultados y discusión}

\section{Ciudadanías alternativas: de lo macro a lo micro}

A propósito de la sociedad cooperativa estudiada, es preciso mencionar que fue fundada en el año 2013 como un grupo de teatro. Su particularidad desde entonces ha sido la naturaleza crítica de sus discursos escénicos, que tocan temas como la violencia, la desigualdad, la situación de las comunidades indígenas del sur de México, la falibilidad de la burocracia o la violencia de género, entre otros. Actualmente, de sus miembros fundadores solo quedan dos. No obstante, en su devenir se han sumado tres nuevos participantes. Entonces, esta cooperativa está integrada por un grupo de cinco individuos de entre 23 y 32 años de edad, mestizos - algunos con ascendencia zoque-, de clase media, con educación universitaria afín a carreras como pedagogía, gestión cultural, actuación y artes plásticas, que se organizan como una sociedad 
cooperativa para generar procesos de mejoramiento comunitario por medio de la producción y promoción de teatro y artes plásticas. Cabe aclarar que, si bien el núcleo duro de la organización está compuesto por cinco personas, estas han conformado una serie de redes de colaboración con artistas y organizaciones locales que fungen como colaboradores externos.

Siguiendo ese tenor, a finales de 2013, la necesidad de encontrar un lugar donde producir sus obras teatrales los condujo a la colonia Bienestar Social. Allí trazarían una serie de interrelaciones comunitarias que los llevarían a generar procesos de identificación y reciprocidad con los habitantes de los sectores populares de la ciudad. Así se puede evidenciar en los siguientes testimonios:

Cuando nosotros estábamos ensayando en la Bienestar, pero no habíamos abierto al público, pues la gente se espantaba por escuchar ruido. Una cosa donde antes no había nadie, de repente hay jóvenes haciendo ruido, haciendo música: "loquitos", dirían ellos. Pero después, cuando nosotros salimos en un periódico, lo compartimos con la gente de la Bienestar y la gente decía: "salieron, ino?". Entonces, de repente los niños te veían en Canal Diez, en el sistema de televisión regional, pues tenían como ese elemento: "órale, este es actor y son del barrio, son de la barriada". Entonces, empezaron a entender que sí es importante, que vale la pena, y ya se hizo como ese aspecto de: "los representantes de la barriada" [...] Fue un puente con la comunidad, porque ya no éramos los gritones sino éramos la gente que hacía teatro, y eso que hacíamos se llamaba teatro, nos dio credibilidad [...] Sobre todo, por el discurso de la obra, creo que nos dio algo que es fundamental en las artes, que es un sentido de apropiación para tu región. En función de eso decidimos ensayar afuera y, claro, los vecinos sacaban sus sillas, y ya de repente el ensayo se convertía en una función porque ya era público. Entonces el sistema de trabajo se hizo tan exigente, porque no puedes fallar en el ensayo porque el vecino te grita: "iEy, ni te lo sabesi". Es un espectáculo que se representa para las personas (M.J., entrevista, 10 de diciembre de 2016).
Era como muy curioso porque la gente nos veía como desconocidos: "Y éstos iquiénes son?, vienen unos chamacos y se encierran". Y ensayábamos teatro, entonces: "dan de gritos iqué está pasando?". Pero ahí nosotros fuimos aprendiendo a socializar lo que hacemos, y el mejor acierto que tuvimos en la Bienestar Social fue sacar las cosas a la calle (A.T., entrevista, 27 de octubre de 2016).

En estos relatos es reconocible el modo en que fueron generando instancias de interacción que les permitieron consolidar relaciones de credibilidad y solidaridad con los habitantes de la colonia. Más tarde, conforme los vínculos con la comunidad se fortalecían, y en la medida que identificaban las condiciones de rezago del lugar, decidieron ampliar su propuesta comunitaria por medio de talleres artísticos, de lectura y danza, entre otros recursos, dirigidos especialmente a niños y jóvenes de la colonia. Una propuesta que más tarde replicarían en la colonia Las Palmas. En ese sentido, fueron las experiencias que tuvieron en Bienestar Social lo que detonó un sentimiento de compromiso con los procesos de mejoramiento social de la colonia. Ello se puede apreciar en los siguientes relatos:

[Se] inició con obras de teatro, que era lo primordial, con lo que se movía, y se enfocaban las obras en general para adolescentes y adultos [...] pero creo que nuestro público ha sido más los niños [...] Cuando los niños querían actuar, salió la idea de dar un taller de actuación; cuando los niños querían música, salió el taller de música [...] y empezamos a trabajar con taller de lecturas (B.J., entrevista, 2 de diciembre de 2016).

Creo que estando ya con la comunidad nos cambió la visión, porque en sí no veníamos con ese cambio de hacer algo social, pero ya estando ahí creo que sí. Nosotros lo notamos, sí era necesario llevar valores y que ellos nos dieran valores también, conocimientos de su comunidad, y nosotros llevar conocimientos de lo que sabemos hacer. Entonces, sí fue muy raro, era mutuo, del conocimiento mutuo (J.V., entrevista, 2 de diciembre de 2016). 
Nosotros desde que llegamos a la Bienestar Social nos topamos con la realidad de una colonia popular en la cual la población necesita tener información en todos los sentidos: ambiente, salud, pero nosotros nos dedicamos al arte, entonces, lo que podemos hacer es aportar desde lo que nosotros tenemos, y es un proyecto netamente para la Bienestar Social [...] nosotros tenemos la ideología de formar mejores ciudadanos a partir de lo que hacemos, no de nuestro ejemplo como personas, sino de nuestro trabajo en función del arte, y por eso apostamos a la colonia como nuestra trinchera; y es para nosotros fundamental defender al barrio porque ya somos parte de él (M.J., entrevista, 12 de octubre de 2016).

Creció tanto el taller que la misma comunidad se integró para mantener la casa en funcionamiento con los talleres, con los requerimientos, con lo demás. Entonces, fue tanto la compañía [...] como los alumnos, los niños, los jóvenes, los padres de familia que solicitaban también las presentaciones de teatro o cine durante los fines de semana. Se involucraban todos (G.V., entrevista, 9 de noviembre de 2016).

Efectivamente, en un principio estos jóvenes no se pensaron como una cooperativa dedicada al mejoramiento social sino, exclusivamente, como una compañía de teatro. No obstante, en la comunidad generaron una serie de sintonías, procesos reflexivos, sentidos de pertenencia y deseos de generar instancias de transformación mediante su labor artística por lo que, a partir de entonces, movilizarían esfuerzos sobre un proyecto comunitario que acercara la producción y el consumo de teatro y artes plásticas a los sectores populares.

En ese sentido, lo relatado da pie para detenerse en dos aspectos. En primera instancia, que la configuración del sentimiento de pertenencia y compromiso de un sujeto hacia un espacio social es un proceso vivido, a la vez que la configuración ciudadana no puede pensarse como un suceso que antecede a la experiencia sino, por el contrario, como un fenómeno corporal, encarnado, que pasa por las impresiones de orden simbólico- expresivo que el sujeto realiza en/con el espacio y lo llevan a identificarse como parte de una historia colectiva. Así, la construcción ciudadana deviene como fruto de las operaciones estéticas, afectivas y reflexivas que realiza el individuo con el territorio.

En segunda medida, permite analizar el modo en que actualmente emergen formas alternativas de participación ciudadana y política ocupadas de atender realidades a las que la política representativa o tradicional no ha llegado. Es observable que, a diferencia de las proclamas ciudadanas de antaño, que trataban de erosionar las disposiciones sociales que estructuraban la vida en un plano vertical o global, estas se emplazan en los espacios próximos, los espacios cotidianos de coexistencia, procurando transformar o influir en las dinámicas que ordenan los tejidos comunitarios.

Autores como Giddens (2000), Santos (1998) y Melucci (1999) afirman que el descreimiento social hacia las instituciones de la política tradicional ha sido el germen de una serie de alternativas de intervención civil que trazan distancia cautelosa de los macroproyectos sociales, o macroracionalidades, para centrarse en lo micro, es decir, en los modos en que se construyen desigualdades en la cotidianidad. Según Giddens (2000), en un mundo caracterizado por el deterioro de las instituciones de participación tradicionales, el poder que solo va de arriba a abajo pierde solvencia para movilizar a las personas, en tanto se aleja de los cambios que transforman la vida cotidiana. Por esta razón emergen, desde el seno de la población civil, alternativas de participación que toman distancia de las formas en que se constituye verticalmente la sociedad - entre Estado y sociedad civil- para centrarse en los procesos horizontales —entre sociedad civil y sociedad civil-.

En contexto, la acción de estos jóvenes es leída como una forma de participación política alternativa en tanto que, por un lado, se emplaza en medio de un complejo interaccional de relaciones materiales y simbólicas que reservan el acceso y consumo de las artes para los sectores sociales que ocupan la escala más alta en la economía del poder local y, por otro, agencia un acercamiento de estos bienes a las capas populares de la sociedad tuxtleca. Bajo esa tesitura, las desigualdades 
no solo son examinadas a partir de las condiciones materiales que distinguen a unas clases de otras, sino también en las posibilidades que tienen para acceder a los bienes culturales. Es decir, el uso y consumo de las artes se convierte en un espacio de confrontación entre actores sociales (García Canclini, 1995).

Así pues, la figura de la sociedad cooperativa es entendida como un recurso de participación política empleado por estos jóvenes para insertarse y mediar en los paisajes de la alteridad y la desigualdad que distancian el consumo de bienes culturales como el arte y el teatro de los sectores populares. De esta manera, por un lado, irrumpen en los lugares donde los programas institucionales encargados de garantizar el mejoramiento y la inclusión social, por medio de políticas que fomenten el aprovechamiento del tiempo y el desarrollo de las artes, no han llegado y, por otro lado, fortalecen la industria artística local en tanto que al socializar este tipo de consumos en todas las capas de la sociedad civil también se generan mercados en los cuales pueden insertarse profesionalmente.

\section{Incertidumbre económica y participación política flexible}

Santos (1998) afirma que la modernidad se constituyó sobre dos pilares: regulación y emancipación. El primero se encuentra fundado en los principios del Estado nacional, el mercado y la comunidad, y el segundo está integrado por los principios de la racionalidad estéticoexpresiva del arte, la racionalidad moral práctica del derecho y la racionalidad cognitiva instrumental de la ciencia. Según Santos, cada uno de estos pilares se consolidó sobre la base de relaciones jerárquicas y antagónicas ordenadas circunstancialmente en el devenir moderno. No obstante, después de la segunda mitad del siglo XX, el mercado se transformó en el eje que normaliza los itinerarios sociales en una escala global y eclipsó el espectro de acción de la comunidad y del Estado, en el pilar de la regulación, e hizo lo mismo con la tecnociencia y la racionalidad estética y jurídica, del lado de la emancipación. El resultado ha sido un desdibujamiento de las fronteras entre ambos pilares de tal magnitud que la emancipación ha terminado absorbida por la regulación, dejando de ser su antípoda para convertirse en su doble (Santos, 1998). Así pues, la intersección de estas dos fuerzas - mercado y tecnociencia - ha propiciado una aceleración y descentralización global de los procesos culturales, políticos y económicos, y ha modificado las texturas de la vida colectiva en todas las localidades del planeta.

Según Beck (2008), el hecho de que el mercado condicione los itinerarios de la sociedad no solo representa una apertura de las fronteras y de los intercambios económicos, sino que se materializa en un sentimiento generalizado de inseguridad económica, puesto que las relaciones de libre competencia, costo/ beneficio y oferta/demanda se agudizan; aquello que llama "El mundo del yo S.A.", donde los actores deben adaptarse al imperativo de los flujos del mercado global.

Volviendo a Santos, se encuentra que en tiempos del capital hipermóvil la resistencia ha perdido su voluntad totalizante. Es decir, dada la capacidad de actuación del mercado, la resistencia se ha visto en la necesidad de reestructurar sus formas de operar para adaptarse a la inseguridad financiera y la hipermovilidad del capital (Santos, 1998). Así pues, elementos del pilar de la emancipación, como las artes, se han adaptado a las modulaciones que impone la circulación global de los capitales. Desde luego, ello no significa que han sido descartadas o que no conserven gran parte de los valores sobre los que se consolidaron, más bien han tenido la necesidad de flexibilizar sus itinerarios, incluso de forma contradictoria, para incluirse en este nuevo proyecto civilizatorio. Bauman (2001) señala al respecto que la flexibilidad de la racionalidad se ha convertido en un elemento vertebral en la época actual.

En un mundo estructurado sobre la lógica del mercado la promoción y producción de bienes artísticos se ha tornado irrelevante, a menos que represente algún tipo de utilidad (Yúdice, 2002). Asimismo, la reducción del gasto público se ha manifestado en una precarización de los recursos destinados a este sector. Por ende, aquellos actores dedicados a esta labor se enfrentan con el hecho de que hacer arte por el arte no es redituable per se, a menos que tenga una 
aplicabilidad, ya sea en la industria cultural o en la esfera del mejoramiento social (Yúdice, 2002).

Al lado de ello, se encontró que la producción artística y teatral tuxtleca es aún incipiente, por una parte debido a las mismas condiciones de atraso estructural de la región, las cuales se manifiestan en poca demanda y, por otra parte, debido a la reducción del gasto público destinado a promover estas en el seno de la población civil. Ante tal escenario, jóvenes como los de esta cooperativa deben generar estrategias que les permitan avivar la industria artística local e insertarse efectivamente en estas circunstancias, de ahí que opten por la vía del mejoramiento social y busquen movilizar sus economías mediante la propuesta comunitaria y recurriendo a las pocas entidades estatales o paraestatales procuradoras de esta labor.

Ciertamente, al igual que otros sectores civiles, los artistas buscan la manera de insertarse profesionalmente en los volubles ritmos del capital. Esta es una de las razones por las cuales en la actualidad se presenta en el contexto tuxtleco una proliferación de sociedades cooperativas dedicadas al trabajo comunitario. Desde luego, ello no significa la ausencia de una identificación con la comunidad tuxtleca ni la falta de un proyecto emancipatorio legítimo - explícito en sus propuestas a favor de la consecución de la equidad en cualquiera de sus manifestaciones: sexual, económica, étnica, de acceso, etcétera-, más bien esboza la forma en que los límites de lo personal, lo económico y lo político se han tornado permeables.

Teniendo en cuenta lo anterior, se considera que el término "participación política flexible" objetiva la forma en que los jóvenes de esta sociedad cooperativa producen y gestionan su lucha social e inserción laboral en los tiempos del capitalismo hipermóvil. Ciertamente, este término permite expresar las relaciones circunstanciales de encuentro, desencuentro, negociación y concesión que se dan entre las estructuras políticas tradicionales y aquellos actores que pugnan por generar un mejoramiento social en los sectores populares de la ciudad. En consecuencia, se piensa la "participación política flexible" como una relación de controversias, confluencias y contradicciones entre los entes reguladores de la política tradicional y formas emergentes de participación política, como esta cooperativa de jóvenes artistas.

En ese orden, a partir del trabajo desarrollado se encontró que, si bien estos jóvenes expresan un descreimiento hacia las instituciones e instancias de participación tradicional, no quieren acabar con ellas sino, más bien, hacer uso estratégico de estas para, por un lado, intervenir, desde su labor, en lo que consideran un daño a la igualdad y, por otro, insertarse laboralmente. En efecto, en un momento histórico en el que el flujo del capital es el principal detonante de la movilización de los actores, no es difícil pensar que los proyectos políticos que emergen de los sectores civiles también se ajusten a él para efectuarse. Después de todo, el desarrollo de cualquier aspiración de la conciencia humana precisa de una serie de recursos para su consumación, y en una época en la que prima el recurso financiero no es extraño que la acción política deba flexibilizarse para adaptarse a tales ritmos.

En relación con ello se encuentran los siguientes relatos:

Somos un colectivo de autogestión, no podemos decir que somos dependientes, porque no, dependemos de nuestro dinero [...] una de las dificultades que tal vez sea la más típica es la económica, que es la que muchas veces te limita, no amarra el espíritu pero sí te amarra el estómago [...] hemos tratado de solventarnos pero a través del trueque. Cambiamos obras de teatro por material o talleres por material, e incluso entre artistas hemos cambiado productos como cuadros por material o cuadros y cuadros [...] tú das un taller yo te doy otro taller (A.T., entrevista, 27 de octubre de 2016).

La dificultad económica es a la que se enfrenta toda compañía, toda empresa. Lo que tenemos en nuestra compañía es que no decimos que nos movemos por el dinero, porque hemos tratado de ver, de la otra forma, qué podemos hacer sin dinero y de eso sobrevivir [...] tratamos de resolver con otras cuestiones cuando nos 
afecta mucho este lado económico (B.J., entrevista, 2 de diciembre de 2016).

Bueno, yo creo que en el aspecto de estar vinculado en el arte aquí en Chiapas es como, ya sé que me voy a morir solo, feo y solo, no, y de hambre; entonces es así como que aprendes a no depender de alguna asociación gubernamental (H.S., entrevista, 2 de diciembre de 2016).

Creo que sufrimos más con lo económico porque sí es muy difícil en este estado sobrevivir del arte, y que te apoyen, o sea, muy difícil. Entonces, lo que tú haces es ver sobre otro lado, o sea, consigues un trabajito o vendes una obra o vendes algo o haces manualidades para otras compañías teatrales y ya le inviertes en tu propia compañía [...] en la economía nos movemos como en varios caminitos para sobrevivir y siempre apoyamos, un porcentaje va para nuestra persona, la vida personal, y otro granito va para la compañía y así sobrevivimos. Sí es un poco difícil aquí en este estado (J.V., entrevista, 2 de diciembre de 2016).

De por sí en este lugar no hay mucho mercado, entonces tratamos de generar mercados y tratamos de generar público, y una manera en que hemos visto que el público llegue es cuando uno le da la entrada libre (A.T., entrevista, 27 de octubre de 2016).

Como se observa, estos jóvenes han significado su agrupación como un espacio autónomo. No obstante, reconocen que el imperativo económico ha sido su principal dificultad. La incertidumbre económica que experimentan la han afrontado mediante propuestas independientes como la apertura de una segunda sede en la colonia Las Palmas y la venta de productos artísticos, entre otros, lo que les permite subvencionar su labor comunitaria y generar ingresos para mantenerse. Se observa también que una de estas propuestas es la formación de redes de colaboración con otras cooperativas y con la comunidad, con quienes construyen economías solidarias sustentadas sobre el trueque o intercambio y la donación de productos, favores y servicios. Estas modalidades económicas se sostienen sobre lazos de apoyo y reciprocidad que han generado a lo largo de su trayectoria. No obstante, al lado de ello han tenido la necesidad de regularizarse en la modalidad de sociedad cooperativa para acceder a otras formas de financiamiento. Así se evidencia a continuación:

La posibilidad de formar una asociación civil es para abarcar un poco más. Y que esos límites que nos ponen ahorita, tal vez por ser una agrupación de autogestión independiente, a veces nos ha tocado escuchar que somos los niños que juegan a soñar, entonces, ya teniendo esa cuestión de ser una asociación, nos tomen en serio para muchas cosas. Es como nuestra meta, poder organizarnos bien, tener esa fuerza y ese, como decir, respaldo, ino?, que te da un papel a veces; que no estamos como muy de acuerdo, pero sí se necesita para seguir haciendo más cosas hacia adelante (A.T., entrevista, 27 de octubre de 2016).

Una de las cosas a las cuales nos hemos enfrentado muchísimo es que las instituciones, las municipalidades, las estatales, las ONG, siempre te piden en convocatorias estar constituidos legalmente para poder acceder a fondos. Porque si bien el trabajo del artista independiente y autogestivo siempre es importante, siempre está como esa brecha entre hacer arte por pasatiempo y hacer arte de manera profesional. Entonces, nos dimos cuenta de que tener una figura legal tiene como más peso en los proyectos que hacemos, y eso hace que las personas nos vean más en serio. Cuando nosotros descubrimos esta forma en la cual otras agrupaciones desarrollan sus proyectos, te digo, otras agrupaciones, no las de aquí, son gente que tiene fundaciones que desarrolla cosas $y$, pues, nosotros dijimos: "bueno, si eso sucede y se puede, pues tenemos que buscar la forma de hacerlo y darnos la oportunidad de crecer en ese sentido" (M.J., entrevista, 12 de octubre de 2016).

Evidentemente, la agrupación no contempló en un principio la opción de institucionalizarse. Sin 
embargo, tuvieron la necesidad de hacerlo como una estrategia para seguir expandiéndose y tener acceso a recursos provenientes de entidades municipales, estatales y no gubernamentales. Así pues, la figura jurídica de la sociedad cooperativa ha sido su recurso de incorporación laboral y política.

En ese orden de ideas, de acuerdo con la Ley General de Sociedades Cooperativas una sociedad cooperativa:

es una forma de organización social integrada por personas físicas con base en intereses comunes y en los principios de solidaridad, esfuerzo propio y ayuda mutua, con el propósito de satisfacer necesidades individuales y colectivas, a través de la realización de actividades económicas de producción, distribución y consumo de bienes y servicios (Ley General de Sociedades Cooperativas, 2018).

En este precepto legal se reconocen tres modalidades de sociedades cooperativas: 1) cooperativas de productores de bienes y servicios, 2) cooperativas de consumidores de bienes y servicios y 3) cooperativas de ahorro y préstamo. En este caso, se considera una cooperativa productora de bienes y servicios aquella:

cuyos miembros se asocien para trabajar en común en la producción de bienes y/o servicios, aportando su trabajo personal, físico o intelectual. Independientemente del tipo de producción a la que estén dedicadas, estas sociedades podrán almacenar, conservar, transportar y comercializar sus productos, actuando en los términos de esta Ley (Ley General de Sociedades Cooperativas, 2018).

A esta agrupación, constituirse como una sociedad cooperativa les permitió que su proyecto comunitario pasara a ser una forma más sostenible de inserción laboral y, del mismo modo, facilitó dar continuidad a su labor en las colonias Bienestar Social y Las Palmas, una tarea que difícilmente se habría consolidado por otra vía. Como se puede observar a continuación, establecerse como cooperativa no solo los legitimó jurídicamente para acceder a convocatorias de distintas instituciones, sino que ello también fue un recurso que les posibilitó convertir su labor en una forma de vida:
Mira, definitivamente la situación del estado, en sí la situación social, política, cultural misma del estado, no te permite hacerlo de manera independiente en todos los sentidos de la palabra [...] estas actividades independientes no te generarían los recursos para seguir trabajando, porque vamos más allá de esa frase cliché de que trabajas por amor al arte, es cierto; o sea, sí se hace, pero también necesitas una remuneración y es una forma de vida. Entonces, si esta forma de vida no te está generando ingresos, solamente por amor al arte, entonces tienes que vincularte a los proyectos estatales o federales para que tú puedas bajar ese recurso y tengas un ingreso. Entonces, es una cuestión de subsistencia también (O.A., entrevista, 18 de noviembre de 2016).

En ese orden, antes de continuar, es importante indicar que se considera que la cooperativa es un recurso de incorporación, pero trazando una relación de distancia cautelosa con cualquier interpretación de corte instrumentalista. Se entiende como el uso estratégico de un producto jurídico que permite a los actores mediar con sus circunstancias estructurales y materiales a fin de concretar proyectos o deseos, ya sean individuales o emancipatorios. Asimismo, implica procesos de gestión, cálculo y negociación con otros actores y con su contexto. Ciertamente, como afirma Yúdice (2002), la agencia política y cultural no se concreta exclusivamente con la enunciación, sino mediante procesos de gestión y negociación con diversos grupos sociales.

En relación con esto cabe mencionar que todos los procesos de incorporación social son llevados a cabo por medio de instituciones. La familia, la escuela, las religiones o el trabajo incorporan a los actores mediante la crianza, la formación o la educación a la experiencia colectiva que los antecede; una vez dentro, estos cuentan con la capacidad de apropiar, resignificar, reproducir o subvertir la normalidad. En el caso analizado, a pesar 
de que estos jóvenes se significan como una asociación independiente, su incorporación política y laboral precisó de una legitimación formal que les permitiera acceder a los recursos necesarios para movilizarse.

Entonces, aunque sus ciudadanías políticas son significadas en distancia de la política dominante y la gubernamentalidad, no puede ser una distancia totalizante, puesto que el acceso a los capitales está condicionado a la pertenencia formal a un tipo de institución. De esta manera, su cooperativa se convierte en una forma de institucionalización política y económica que los legitima jurídicamente y les da la posibilidad de acceder a los recursos destinados a nivel estatal y federal para mejoramiento social.

En ese sentido, al lado de su independencia, trazan relaciones de dependencia con la estatalidad y con otras entidades gubernamentales como el Consejo Estatal para las Culturas y las Artes de Chiapas (CONECULTA) y el Instituto Tuxtleco de Arte y Cultura (ITAC), dedicadas al fomento de las artes en la sociedad de Tuxtla Gutiérrez:

En ocasiones acudimos a CONECULTA, ellos nos apoyan. Llevamos la carpeta digital y una carpeta en físico y esperamos la respuesta. Ya cuando ellos nos dan la respuesta nos dicen a qué lugar tenemos que ir. Y si va a haber un pago, nosotros tenemos que sacar antes de nuestra bolsa para poder acudir a ese lugar, ejecutar la obra, tomar registro y luego regresar para poder traer los comprobantes de que la obra sí se hizo en ese lugar. Y ya después recibimos el pago, y ese mismo pago a veces sirve para mejorar la obra o para hacer alguna otra cosa (A.T., entrevista, 27 de octubre de 2016).

No obstante, en referencia a estas alianzas con organismos federales y municipales también señalan que en muchos casos son contraproducentes:

En cuestiones de hacer trabajos con compañías del municipio es que no pagan a tiempo. Entonces, si dependes, lo que tú vas a ganar en ese trabajo ya lo tienes gastado, ya lo tienes endeudado, entonces la luz sigue corriendo, la renta también, y, pues, comes diario (A.T., entrevista, 27 de octubre de 2016).

Federalmente ha habido recortes en salud y educación, entonces sí te merma, porque a veces es el ingreso más fuerte y constante, y en el cual sabes que tal vez te van a pagar algún día, y sabes y dices: "al menos me lo están ahorrando”. Entonces, sí, es a veces fuerte (H.S., entrevista, 2 de diciembre de 2016).

Yo creo que a nivel estatal la problemática cultural aquí en Chiapas es un poco fuerte [...] en sí no es tanto el sistema de CONECULTA, creo que a veces hay personas que no están capacitadas cien por ciento para estar en esas oficinas. No sé, igual si pones a un abogado en un área de cultura para obras, pues nada que ver. Pero desafortunadamente es una cadenita que viene en gobierno, hay personas acomodadas, plazas vendidas (B.J., entrevista, 2 de diciembre de 2016).

A pesar de que recurren de forma permanente a estas instancias gubernamentales, en sus relatos se observa que se producen acontecimientos que los llevan a mantener cierta distancia y a adoptar una actitud de descreimiento hacia este tipo de órganos, como la disminución de los recursos, la mala administración, el clientelismo o el incumplimiento de los contratos, entre otros factores. De ahí que recurran a otros organismos de carácter paraestatal e internacional:

Si no está CONECULTA buscamos otras alternativas, y si no están otras dependencias gubernamentales, podrá haber compañías comunitarias o independientes que también estén realizando lo que quizá nosotros queremos hacer [...] sabemos que ahora en cualquier lugar estamos con un déficit muy grande y no sólo en lo cultural [...] pero eso es lo que aquí en Chiapas a otras compañías y a otros artistas les ha beneficiado, porque les ha dado las herramientas, al no apoyar, para que independientemente logren concretar otras cosas (B.J., entrevista, 2 de diciembre de 2016). 
Hay proyectos de la ONU, de UNESCO, en cuestiones de proyectos comunitarios, en los cuales te dan la financiación; tú lo realizas y preguntas, y si hay una comprobación de que realmente sí le ayuda a la comunidad a generar un cambio social, entonces te compran ese proyecto y sigues manejándolo. Claro, son varias cuestiones (H.S., entrevista, 2 de diciembre de 2016).

En efecto, afirmar que mantienen una distancia categórica de las instituciones tradicionales sería reducir lo que hacen explícito, como del mismo modo lo sería decir que son totalmente dependientes puesto que, como se mencionó, tienen otras propuestas mediante las cuales trazan distancia económicopolítica de las instituciones tradicionales. Sería más adecuado señalar que las fronteras entre la independencia y la dependencia son porosas y contingentes. Incluso en algunos momentos trazan relaciones de interdependencia con instituciones convencionales como los partidos políticos, tal como se observa en el siguiente relato:

Desde el principio dijimos que no nos íbamos a relacionar ni en política ni en religión, no íbamos a inclinarnos en ningún lado. Si en dado caso quisieran contratar servicios es diferente, pero no vamos a favorecer a nadie porque entonces ahí chocaría todo [...] Y nos ha tocado. El último caso nos pasó con Fernando [el presidente municipal]; fuimos a una cuestión que nos contrataron para un festival y estaba un candidato en ese mismo momento saludando al pueblo y llegó a buscar la foto con la agrupación, pero nosotros, aparte de colocarnos en contraluz para ocasionar ese efecto de oscuridad, posamos como, así, teniendo una expresión en la que sí estamos conviviendo contigo, pero somos otro grupo; por ejemplo, el chino hizo muecas. Y esa es la idea, porque hay gente que abraza a la persona idolatrándola. Con nosotros: "iuna foto?" vale, tú estás viniendo a tomarte la foto con nosotros, no nosotros nos la estamos tomando contigo. No buscamos esa imagen (A.T., entrevista, 17 de noviembre de 2016).
Es muy fácil de repente decir soy [...] y me voy con un partido [...], y sería muy fácil técnicamente, pero no hay como esencia. Si de repente algún partido llega y dice: "necesito un sistema de talleres". Sí, nosotros conseguimos la gente, los asesoramos capacitamos al personal para que ellos lo hagan, pero que nosotros vayamos a una guerra que no es nuestra guerra, creo que lo que estamos haciendo es mucho más (M.J., entrevista, 18 de noviembre de 2016).

En contexto, cuando se habla de relaciones de interdependencia se hace referencia a los espacios de mutua colaboración que se producen entre las sociedades cooperativas de este tipo y los partidos políticos o instituciones de gobierno. Como se observó en este caso, si bien algunas cooperativas se significan en distancia y descreimiento de la política tradicional - por causa de su inefectividad y corrupción - en su búsqueda de recursos financieros tienen la necesidad de generar alianzas circunstanciales en las que ambas partes cumplen sus objetivos. De ahí que se hable de relaciones flexibles.

En suma, sociedades cooperativas como la analizada aquí no solo trazan relaciones de independencia y dependencia con los órganos de la política tradicional; circunstancialmente, son interdependientes. Así, por un lado, las cooperativas se insertan económicamente a partir de su vinculación con instituciones tradicionales y, por otro lado, las instituciones de gobierno se benefician de la existencia e independencia de estas cooperativas puesto que representan un puente entre sus propios proyectos y la comunidad tuxtleca.

\section{Reflexiones finales}

Primeramente, es necesario subrayar que lo expuesto aquí debe leerse en el tenor de los actores involucrados, los recursos que ponen en juego, los proyectos trazados y las condiciones estructurales de su contexto, ello con el fin de evitar interpretaciones universalistas de cualquier tipo. Ciertamente, es necesario considerar que las formas de participación de los jóvenes 
tuxtlecos son diversas y polimórficas, por lo que no se pueden reducir a un formato particular.

Al lado de ello, se pudo observar que formas de participación política como esta se han distanciado de las atestiguadas durante los siglos XIX y XX, por lo que es necesario construir nuevos marcos referenciales y categorías explicativas que posibiliten su comprensión. En efecto, las luchas políticas actuales involucran ante todo lo cotidiano y lo subjetivo, por lo que atrás ha quedado aquella línea divisoria entre subjetividad, ciudadanía y emancipación (Santos, 1998).

Por otra parte, si bien la agremiación voluntaria ha jugado un papel primordial en el devenir de la modernidad, en tanto fue el germen de los sindicatos, los partidos políticos y las logias, entre otras agrupaciones, se observa que las sociedades cooperativas representan una dislocación en los formatos de asociación política. La razón es que son otros los actores que las constituyen - jóvenes, mujeres, afros, indígenas, comunidades sexualmente diversas, etcétera- y otros los proyectos trazados. A su vez, exponen nuevas formas de atomización política, evidenciables en lo reducidas que son si se comparan con otras formas de agremiación tradicional.

Efectivamente, en tiempos del capitalismo hipermóvil los proyectos políticos tienden a abandonar los macrolugares de enunciación para adoptar microespacios, como la cooperativa o la asociación. Desde estos emplazamientos, micro, se ponen en escena una heterogeneidad de formas de actuación política que, si bien se distancian, circunstancialmente, de las formas tradicionales - lo macro-, también se encuentran en permanente tensión y negociación con estas, por lo que no se pueden asumir lecturas deterministas.

Del mismo modo, se puede evidenciar que en la actualidad las fronteras que tradicionalmente dividían la producción artística, la intervención social y la lucha por las desigualdades se han desdibujado como consecuencia de la expansión del mercado en todas las dimensiones de la vida. Aunque el arte siempre tuvo un perfil contrahegemónico, hasta hoy en día este no traspasaba la frontera de la experiencia estética, además de que su consumo y producción se encontraba reservado para ciertos grupos. Por su lado, la intervención social estaba restringida para aquellos actores pertenecientes a las instituciones destinadas a garantizar el bienestar social. Del mismo modo, la lucha por las desigualdades era protagonizada por otros actores, generalmente partidos políticos, obreros y sindicatos — siendo las desigualdades materiales su único detonador-. No obstante, en tiempos del capitalismo hipermóvil, el arte y la experiencia estética han dejado de ser una prioridad para el mercado; las instituciones encargadas de intervenir en lo social se han visto reducidas por su ineficacia para cumplir su función y por la reducción de los gastos públicos; y las luchas por las desigualdades se han tornado heterogéneas y atomizadas. En tales condiciones, todos estos sectores han dejado de ocupar el lugar que gozaron tradicionalmente - han perdido su aspiración totalizante-, a tal punto que las fronteras entre sí se han tornado difíciles de delimitar.

En lo concerniente a la producción artística, dado que su valor estético se ha visto disminuido en ventaja de su utilidad, aquellos actores que se dedican a la producción artística se enfrentan con el hecho de que hacer arte por el arte mismo no genera ningún tipo de ganancia, a menos que sea empleado para insertarse en la industria cultural o para generar procesos de mejoramiento humano. En consecuencia, encuentran en las sociedades cooperativas un recurso que les permite insertarse profesionalmente en los actuales ritmos del capital y generar procesos de bienestar comunitario.

Por último, vale señalar que el aumento del número de sociedades cooperativas que se evidencia actualmente en ciudades como Tuxtla Gutiérrez puede ser interpretado de tres maneras: en primer lugar, como un cambio en la racionalidad política de los actores sociales, que los lleva a buscar alternativas de participación para atender las carencias y vacíos que deja la política representativa tradicional. De ser así, seríamos partícipes de un momento histórico en que se transita de un modelo democrático representativo a un modelo democrático participativo. Otra interpretación sería que el aumento de estas cooperativas obedece a la precarización de los procesos de inserción profesional, al detrimento de garantías laborales como 
el derecho a contratos justos y bien remunerados y a la desestructuración del estado de bienestar en ventaja del estado neoliberal, que relegaría la tarea de garantizar el mejoramiento social a las clases medias. Una última interpretación integraría ambas miradas.

\section{Notas}

${ }^{1}$ Por respeto a la confidencialidad, no se mencionarán el nombre de la cooperativa ni de sus integrantes en este artículo.

2 Bienestar Social es una colonia popular de clase media baja ubicada en el lado sur oriente de la ciudad, caracterizada por problemas de desatención en materia de servicios públicos, rezago social y niveles significativos de inseguridad.

${ }^{3}$ Las Palmas es una colonia popular de clase media alta ubicada en el lado norte oriente de la ciudad.

${ }^{4}$ Hoy en día, la velocidad y densidad de los flujos financieros globales es inédita, aunado al hecho de que el valor del dinero cambia vertiginosamente conforme a las fluctuaciones del mercado; esta situación no solo implica una ampliación de los intercambios mercantiles, sino que representa la instalación de un ritmo de vida más acelerado, aumento de los costos de vida, mayor demanda de especialidad e innovación, precarización de los contratos laborales, incremento de la competencia y la necesidad de adaptarse a los ritmos del capital.

\section{Referencias}

Aguilar Ortega, Teodoro (2016). "Desigualdad y marginación en Chiapas". Península, 12(2), juliodiciembre, 143-159.

Bauman, Zygmunt (2001). La globalización. Consecuencias humanas. México: FCE.

Benedicto, Jorge y María Luz Morán (2003). “Los jóvenes, ¿ciudadanos en proyectos?”. En Jorge Benedicto y María Luz Morán (eds.), Aprendiendo a ser ciudadanos. Experiencias sociales y construcción de la ciudadanía entre los jóvenes. Madrid: Injuve, pp. 39-64.

Beck, Ulrich (2008). Globalización e inseguridad creciente. Barcelona: Paidos,
CDI (Comisión Nacional para el Desarrollo de los Pueblos Indígenas) (2017). Indicadores socioeconómicos de los Pueblos Indígenas de México. México: CDI. Disponible en: https://www.gob.mx/cdi/documentos/indicadoressocioeconomicos-de-los-pueblos-indigenas-demexico-2015

CONEVAL (Consejo Nacional de Evaluación de la Política de Desarrollo Social) (2015). Pobreza a nivel municipio 2015. México: CONEVAL. Disponible en: https://www.coneval.org.mx/coordinacion/entidades/ Chiapas/Paginas/pobreza_municipal2015.aspx

CONEVAL (Consejo Nacional de Evaluación de la Política de Desarrollo Social) (2019). Diez años de medición de pobreza en México, avances y retos de política social Chiapas. México: CONEVAL. Disponible en: https://www. coneval.org.mx/coordinacion/entidades/Documents/ Comunicados_Pobreza_2018/COMUNICADO_ MEDICION_POBREZA_2018_CHIAPAS.pdf

Corporación Latinobarómetro (2016). Informe 2016. Buenos Aires: Latinobarómetro. Disponible en: http://www. latinobarometro.org/LATDocs/F00005843-Informe LB_2016.pdf

García Canclini, Néstor (1995). Consumidores y ciudadanos. Conflictos multiculturales de la globalización. México: Grijalbo.

Giddens, Anthony (2000). Un mundo desbocado. Los efectos de la globalización en nuestras vidas. México: Taurus.

Ley General de Sociedades Cooperativas (2018). Diario Oficial de la Federación, 19 de enero. Disponible en http:// www.diputados.gob.mx/LeyesBiblio/pdf/143_190118. pdf

Melucci, Alberto (1999). "Los movimientos sociales en la sociedad contemporánea”. En Alberto Melucci, Acción colectiva, vida cotidiana y democracia. México: COLMEX, pp. 69-93.

Ramírez Saíz, Juan Manuel (2011). "Dimensiones constitutivas y ejes estructurantes de la ciudadanía". En Estudios Políticos (26), 11-35.

Santos, Boaventura de Sousa (1998). De la mano de Alicia. Lo social y lo político en la posmodernidad. Bogotá: Siglo del Hombre/Uniandes.

Yúdice, George (2002). El recurso de la cultura. Usos de la cultura en la era global. Barcelona: Gedisa. 